\title{
The impact of the Medicines Control Council backlog and fast-track review system on access to innovative and new generic and biosimilar medicines of public health importance in South Africa
}

\author{
H M J Leng, A M Pollock, D Sanders \\ Dr Henry Leng is a senior researcher in the School of Public Health at the University of the Western Cape. Prof. Allyson Pollock is Professor of Public \\ Health Research and Policy at Queen Mary University, London, UK. Prof. David Sanders is Emeritus Professor in the School of Public Health at the
} University of the Western Cape, Cape Town.

Corresponding author: H M J Leng (hmjleng@gmail.com)

The fast-track registration policy of the South African (SA) National Department of Health (DoH) allows for rapid registration of new medicines of public health importance and of all medicines on the Essential Medicines List, most of which are generics. No limit is placed on the number of generic brands of a medicine that can be submitted for fast-track registration. This, together with resource constraints at the regulator, may delay access to important new medicines, new fixed-dose combinations of critical medicines or affordable versions of biological medicines (biosimilars). One reason for not limiting the number of fast-track generic applications was to promote price competition among generic brands. We found this not to be valid, since market share correlated poorly with price. Generic brands with high market share were, mostly, those that were registered first. We propose that the number of generic brands accepted for fast-tracking be limited to not more than seven per medicine.

S Afr Med J 2016;106(4):350-353. DOI:10.7196/SAMJ.2016.v106i4.10237

In a recently published article, we tested the widely held belief, particularly among those in the pharmaceutical industry, that the backlog in medicine registration applications at the Medicines Control Council (MCC) was a barrier to access to affordable generic medicines ${ }^{[1]}$ In the study, we investigated the availability of generic products of eight tracer medicines (amlodipine, ciprofloxacin, fluoxetine, lamivudine, metformin, oxytocin, rifampicin and simvastatin) that are commonly used in the treatment of the most prevalent diseases in SA. ${ }^{[2]}$ Availability was assessed based on the number of generic products for each tracer medicine that had been registered at the time of the study in 2012, as well as the number of generics that were being marketed. We found that for most of the tracer medicines, more generics had been registered than were being sold in the market. When data were aggregated, they showed that only $54 \%$ of all registered generic brands for the eight medicines were marketed, which suggests that the backlog was not a hindrance to access to these medicines.

In 2003, the DoH implemented a fast-track registration policy, not only for new chemical entities (NCEs) considered essential for national health and which may not be on the Essential Medicines List (EML), but also for all medicines on the EML, the majority of which are generics. ${ }^{[3,4]}$ We found that for the period between 2007 and 2012, more generic medicines were registered through expedited review (fast track) than NCEs. ${ }^{[1]}$ Since no limit is placed on the number of generics of a particular medicine that can be fast-tracked, it is likely that several generic applications may be in the fast-track system when many generic products for such medicines have already been registered. It is, therefore, not surprising that the fast-track review process, which should lead to a registration decision timeline of not more than 9 months after first submission, ${ }^{[3]}$ is now also taking considerably longer. A backlog is therefore likely to be present, even in the expedited registration pathway. This, coupled with current shortcomings, such as insufficient skilled manpower and poor infrastructure at the MCC, ${ }^{[5]}$ could prevent innovative as well as cost-effective and new fixed-dose combination (FDC) therapies from reaching patients timeously.

According to the minutes of the Industry Task Group meeting held in March 2015, ${ }^{[6]}$ the MCC has been allocating applications for review received from January until March 2012. This implies that the applications that make up the backlog are all those received up to December 2011 and which have not yet been reviewed. These applications will therefore only be evaluated once the MCC has acquired substantial additional capacity to start reviewing backlog applications.

A class of important and potentially cost-effective medicines that may be part of the backlog is biosimilar medicines. These are products that are similar, i.e. not identical, to innovator biopharmaceuticals of erythropoietin, filgrastim, growth hormone, infliximab, etc. that are produced by modern biotechnological methods and are already off patent. ${ }^{[7]}$ While many countries in the European Union, as well as Canada, Australia, Korea and even the USA, have registered such products, SA has yet to register its first biosimilar. Biosimilars are significantly cheaper than their innovator counterparts ${ }^{[8]}$ and, consequently, more patients would have access to these medicines once they are registered. In Europe, biosimilars of somatropin, erythropoietin and filgrastim have been available since before $2010{ }^{[9]}$ Considerable experience has therefore already been gained with the use of these products, so that doubts about their safety and efficacy should no longer exist. The MCC should, therefore, alter its strategy for the allocation of applications for evaluation from using 
Table 1. Date of registration, single exit price per dosage unit and market share of selected tracer medicines as at December 2012 (names of registration holders for each product are included)

\begin{tabular}{|c|c|c|c|c|c|}
\hline $\begin{array}{l}\text { Active pharmaceutical } \\
\text { ingredient } \\
\text { (strength/dosage unit) }\end{array}$ & Brand name & $\begin{array}{l}\text { Date of registration } \\
\text { (YYYY/MM/DD) }\end{array}$ & Holder of registration certificate & $\begin{array}{l}\text { Price/unit } \\
\text { (ZAR) }\end{array}$ & $\begin{array}{l}\text { Market share by } \\
\text { volume (\%) }\end{array}$ \\
\hline \multirow[t]{5}{*}{ Alendronate (70 mg/tablet) } & Osteobon & $2005 / 07 / 29$ & Cipla Medpro (Pty) Ltd & 45.60 & 44.4 \\
\hline & Fosamax $^{*}$ & $2002 / 03 / 26$ & MSD (Pty) Ltd & 93.84 & 6.3 \\
\hline & Osteonate & $2010 / 11 / 26$ & Pharma Dynamics (Pty) Ltd & 38.29 & 1.7 \\
\hline & Fosagen & $2006 / 02 / 17$ & Mylan (Pty) Ltd & 52.54 & 0.9 \\
\hline & $\begin{array}{l}\text { Sandoz } \\
\text { Alendronate }\end{array}$ & $2006 / 12 / 01$ & Sandoz SA (Pty) Ltd & 56.48 & 0.3 \\
\hline \multirow{5}{*}{$\begin{array}{l}\text { Amlodipine }(10 \mathrm{mg} / \\
\text { tablet) }\end{array}$} & Amloc & $2004 / 09 / 17$ & Pharma Dynamics (Pty) Ltd & 3.61 & 37.8 \\
\hline & Ciplavasc & $2005 / 02 / 11$ & Cipla Medpro (Pty) Ltd & 3.50 & 19.3 \\
\hline & Lomanor & $2005 / 09 / 23$ & Pfizer Laboratories (Pty) Ltd & 3.08 & 10.0 \\
\hline & Norvasc ${ }^{\star}$ & $1991 / 11 / 26$ & Pfizer Laboratories (Pty) Ltd & 6.71 & 4.6 \\
\hline & Amlate & $2006 / 08 / 11$ & Dr Reddy's Laboratories (Pty) Ltd & 3.46 & 3.1 \\
\hline \multirow{8}{*}{$\begin{array}{l}\text { Ciprofloxacin }(250 \mathrm{mg} / \\
\text { tablet) }\end{array}$} & Cifloc & $2001 / 10 / 08$ & Dr Reddy's Laboratories (Pty) Ltd & 1.31 & 21.6 \\
\hline & Ciploxx & $2003 / 01 / 24$ & Cipla Life Sciences (Pty) Ltd & 1.25 & 17.3 \\
\hline & Ciprobay* & $1990 / 06 / 12$ & Bayer (Pty) Ltd & 10.09 & 10.6 \\
\hline & $\begin{array}{l}\text { Austell } \\
\text { Ciprofloxacin }\end{array}$ & $2004 / 07 / 02$ & Austell Laboratories (Pty) Ltd & 1.07 & 10.2 \\
\hline & Ciprol & $2004 / 07 / 23$ & Arrow Pharma South Africa (Pty) Ltd & 1.19 & 6.4 \\
\hline & Ciprogen & $2003 / 09 / 05$ & Xixia Pharmaceuticals (Pty) Ltd & 1.39 & 5.8 \\
\hline & Bio-Ciprofloxacin & $2005 / 10 / 09$ & Biotech Laboratories (Pty) Ltd & 0.97 & 4.5 \\
\hline & Orpic & $2002 / 09 / 20$ & Pharmacare Limited & 1.26 & 2.9 \\
\hline \multirow{10}{*}{$\begin{array}{l}\text { Fluoxetine ( } 20 \mathrm{mg} / \\
\text { capsule) }\end{array}$} & Nuzak & $1998 / 05 / 25$ & Cipla Medpro (Pty) Ltd & 1.22 & 45.7 \\
\hline & Lorien & $1996 / 03 / 27$ & Pharmacare Limited & 1.18 & 24.0 \\
\hline & Lilly-Fluoxetine & $1995 / 10 / 25$ & Eli Lilly (SA) (Pty) Ltd & 3.88 & 11.7 \\
\hline & Rezak & $2003 / 03 / 07$ & Ranbaxy (SA) (Pty) Ltd & 0.74 & 4.5 \\
\hline & Ranflocs & $2003 / 04 / 25$ & Dr Reddy's Laboratories (Pty) Ltd & 0.70 & 4.3 \\
\hline & $\begin{array}{l}\text { A-Lennon } \\
\text { Fluoxetine }\end{array}$ & $2001 / 09 / 21$ & Zydus Healthcare SA (Pty) Ltd & 0.76 & 2.3 \\
\hline & Zydus-Fluoxetine & $2005 / 06 / 03$ & Pharmacare Limited & 0.74 & 2.2 \\
\hline & Prohexal & $2000 / 12 / 13$ & Sandoz SA (Pty) Ltd & 1.23 & 1.9 \\
\hline & Prozac $^{*}$ & $1986 / 12 / 31$ & Eli Lilly (SA) (Pty) Ltd & 14.24 & 1.2 \\
\hline & Actor Fluoxetine & $2003 / 03 / 07$ & Cipla Medpro (Pty) Ltd & 1.14 & 1.0 \\
\hline \multirow{9}{*}{$\begin{array}{l}\text { Metformin }(500 \mathrm{mg} / \\
\text { tablet) }\end{array}$} & Glucophage $^{*}$ & $1975 / 04 / 25$ & Merck (Pty) Ltd & 0.49 & 49.1 \\
\hline & Mylan Metformin & $2000 / 12 / 13$ & Sandoz SA (Pty) Ltd & 0.34 & 14.4 \\
\hline & Sandoz Metformin & $1984 / 03 / 26$ & Mylan (Pty) Ltd & 0.35 & 11.5 \\
\hline & Arrow Metformin & $2005 / 09 / 23$ & Arrow Pharma South Africa (Pty) Ltd & 0.36 & 4.4 \\
\hline & Metforal & $2002 / 09 / 20$ & Adcock Ingram Limited & 0.35 & 3.4 \\
\hline & Metored & $2008 / 08 / 15$ & Pharmaplan (Pty) Ltd & 0.34 & 3.1 \\
\hline & Accord Metformin & $2009 / 12 / 04$ & Accord Healthcare (Pty) Ltd & 0.32 & 2.6 \\
\hline & Gluconorm & $2007 / 10 / 05$ & Be-Tabs Pharmaceuticals (Pty) Ltd & 0.34 & 2.3 \\
\hline & Austell Metformin & $2005 / 09 / 23$ & Austell Laboratories (Pty) Ltd & 0.36 & 1.8 \\
\hline
\end{tabular}

a specific date of submission such as January 2012 (as it currently does) to selecting product classes or types for which there is a public need, irrespective of when the applications of such products were submitted.
The lack of restrictions on the use of the fast-track review system, such as placing a limit on the number of generics of a specific medicine that can be reviewed and registered via this process, can result in delays in the registration and availability of medicines of 
Table 1. (continued) Date of registration, single exit price per dosage unit and market share of selected tracer medicines as at December 2012 (names of registration holders for each product are included)

\begin{tabular}{|c|c|c|c|c|c|}
\hline $\begin{array}{l}\text { Active pharmaceutical } \\
\text { ingredient } \\
\text { (strength/dosage unit) }\end{array}$ & Brand name & $\begin{array}{l}\text { Date of registration } \\
\text { (YYYY/MM/DD) }\end{array}$ & Holder of registration certificate & $\begin{array}{l}\text { Price/unit } \\
\text { (ZAR) }\end{array}$ & $\begin{array}{l}\text { Market share by } \\
\text { volume (\%) }\end{array}$ \\
\hline \multirow{10}{*}{$\begin{array}{l}\text { Simvastatin } \\
(20 \mathrm{mg} / \text { tablet })\end{array}$} & Adco-Simvastatin & $2002 / 09 / 20$ & Adcock Ingram Limited & 1.02 & 58.3 \\
\hline & Simvacor & $2002 / 11 / 15$ & MC Pharma (Pty) Ltd & 1.02 & 7.0 \\
\hline & Cipla-Simvastatin & $2006 / 10 / 06$ & Cipla Life Sciences (Pty) Ltd & 0.97 & 6.9 \\
\hline & Simvotin & $2004 / 05 / 28$ & Ranbaxy (SA) (Pty) Ltd & 1.10 & 5.8 \\
\hline & Aspen Simvastatin & $2005 / 07 / 29$ & Pharmacare Limited & 1.10 & 5.4 \\
\hline & Michol & $2007 / 10 / 05$ & Ingelheim Pharmaceuticals (Pty) Ltd & 1.54 & 4.4 \\
\hline & Zocor* & $1990 / 04 / 02$ & MSD (Pty) Ltd & 2.45 & 3.1 \\
\hline & Arrow Simvastatin & $2006 / 04 / 07$ & Arrow Pharma South Africa (Pty) Ltd & 1.07 & 2.2 \\
\hline & Choleste & $2007 / 10 / 05$ & Be-Tabs Pharmaceuticals (Pty) Ltd & 1.07 & 1.4 \\
\hline & Biovac Simvastatin & $2006 / 12 / 01$ & Arrow Pharma South Africa (Pty) Ltd & 1.07 & 0.9 \\
\hline
\end{tabular}

public health importance. In our previous study, we found that changes in the treatment guidelines for tuberculosis (TB) may have made some FDC products containing rifampicin obsolete, causing them not to be marketed. New FDC formulations, and even new drugs for the prevention and treatment of multidrugresistant TB, even if fast-tracked, could take significantly longer than the specified 9 months expedited review and registration decision timeline. An example is an application for the registration of a generic version of linezolid that was submitted for fast-track review in May 2013 for the treatment of drug-resistant TB (DRTB). When a final decision on the product was still outstanding more than 16 months after its submission, activists handed over a letter addressed to the Registrar of Medicines, signed by clinicians, civil society organisations and patients with DR-TB, demanding its immediate registration. ${ }^{[10]}$ The product was eventually registered in November 2014 and a second one in March 2015. At least six other generic linezolid tablet formulations $(600 \mathrm{mg} / \mathrm{tablet})$, all submitted as fast-track applications, are currently under review. This raises an important issue that needs to be considered if the fast-track review process is to be amended to improve its effectiveness: what should be the number of generics of a specific medicine that are allowed to be fast-tracked, to ensure not only timeous availability but also affordability through robust competition? Should the additional six applications also have been allowed in the fast-track system, which, with the current limited number of evaluators, will take preference over other fast-track applications for medicines for which there may potentially be no alternatives, or if alternatives exist, may not be as effective as the new medicine?

Table 1 gives the single exit price per dosage unit (i.e. tablet or capsule) for several brands of each of six tracer medicines, their percentage market share by volume and their date of registration. Whereas the price difference between the generic products and their corresponding innovator is substantial in almost all cases, the variation in price among generics of a specific medicine is often not as large. Exceptions include where the patent holder of the innovator markets a generic version of its own product (a clone or autogeneric) as is the case with the fluoxetine generic Lilly-Fluoxetine which, although priced at only $27 \%$ of the cost of the innovator product, Prozac, was three times more expensive than the market leader (Nuzak).
Another observation is that the market leader for a specific medicine is not necessarily the cheapest brand. In the case of the alendronate generics, for example, the cheapest product was Osteonate, which cost $16 \%$ less than the market leader, Osteobon. Yet, it only had a market share of $1.5 \%$, whereas Osteobon had a market share of $44.6 \%$. The higher market share was most likely due to earlier entry, since Osteobon was registered before Osteonate. In fact, for most of the other medicines in the sample, the market leader or its follower was registered first. An interesting observation was that one innovator product retained its dominant market position after generics entered. The metformin originator product, Glucophage, was still the market leader (at $49.1 \%$ market share) even though it was priced $35 \%$ higher than the cheapest generic (Accord Metformin, with a market share of $2.6 \%$ ) and $31 \%$ higher than the generic with the next highest market share (Mylan Metformin, with a market share of $14.4 \%$ ). This price difference is similar to that found between the highest and lowest priced generics of some of the other tracer medicines. For example, for ciprofloxacin and alendronate, the difference in price between the most and least expensive generics was $40 \%$ and $48 \%$, respectively. The price difference between the innovator and generic market leader for the other medicines ranged from $86 \%$ for amlodipine to $1067 \%$ for fluoxetine. Glucophage was therefore priced at the same level as generics, which ensured its dominant market position.

Competition theory predicts that as more competitors enter a market, prices of products will fall. Hence, registering a large number of generics should lower the cost of medicines, increasing their accessibility. Our data show, however, that increasing availability through registration of more generics does not necessarily lead to greater access, as measured by percentage market share, even if these newly registered generics are priced lower than those already in the market. Regression analysis further confirmed the weak relationship $\left(R^{2}<0.05\right)$ between price and market share (data not shown). This suggests that at the prevailing price level of generics, other factors are more important determinants of market share. One such factor is market entry, since among our sample of six medicines, the brands with the highest market share were those that had been among the first to obtain registration.

The data above, although based on a small sample of medicines, suggest that the contention of promoting competition by registering several generic brands of a medicine to ensure low prices and, hence, affordability to the patient, may not be valid. Affordability appears 
to be a function more of the price difference between the innovator and generics as a group, which can be substantial $(>80 \%)$, as this has been shown to erode the market share of the innovator. Differences in prices among generic brands do not correlate with market share. What is far more important is market entry. Therefore, in the allocation of fast-track status to generic applications for a medicine that has gone off patent, the promotion of competition should not be a prime consideration, particularly in view of the capacity constraints at the MCC, i.e. the limited number of evaluators currently available. The fasttrack system should at all times be responsive and, consequently, must be reserved for new medicines, a novel formulation or combination of existing medicines based on new treatment guidelines, the first generic of an off-patent medicine, or for unique biologicals such as vaccines and biotechnology products, including biosimilars.

Finally, medicines with small local markets for which there are few registered products and suppliers are vulnerable to stock-outs when suppliers decide to discontinue their products. Oxytocin is one such product, with only three registered brands, and which had a market value of ZAR24.9 million in 2012. This is considered small relative to that of other products such as amoxicillin (ZAR441.4 million), tenofovir (ZAR467.5 million), ibuprofen (ZAR498.4 million) and paracetamol (ZAR1.697 billion). The product is only used in the hospital setting and requires cold-chain storage. These factors probably discourage local companies from including oxytocin formulations in their product portfolio. A more recent case involves intravenous rifampicin, which was under threat of being discontinued by the only supplier for this product. ${ }^{[1,12]}$
It is important, therefore, to ensure that the fast-track system is immediately accessible when applications for such marketvulnerable products are received by the MCC.

1. Leng HMI, Sanders D, Pollock AP. Pro-generics policies and the backlog in medicines registration in South Africa: Implications for access to essential and affordable medicines. GaBI J 2015;4(2):58-63. DOI:10.5639/gabij.2015.0402.014

2. Coovadio H Jewkes R Barron P. Sanders D. McIntyre D. The health and health system of South Africa: Historical roots of current public health challenges. Lancet 2009;374(9692):817-834. DOI:10.1016/S0140-6736(09)60951-X roots of current public health challenges. Lancet 2009;374(9692):817-834. DOI:10.1016/S0140-6736(09)60951-X
Medicines Control Council. General information guideline, 2008. www.mccza.com (accessed 27 3. Medicines Control Council. Gener
March 2013 and 19 October 2015).

March 2013 and 19 October 2015).
4. National Department of Health of South Africa. National Essential Medicines List. http://www.health. gov.za/index.php/component/phocadownload/category/196 (accessed 9 March 2016).

5. Report of the Ministerial Task Team on the restructuring of the Medicines Regulatory Affairs and Medicines Control Council and recommendations for the new Regulatory Authority for Health Products of South Africa, 2008. http://www.gov.za/sites/www.gov.za/files/Report\%20of\%20Ministerial\%20Task\%20 Team\%20on\%20Restructuring\%20of\%20Medicines\%20Regulatory\%20Affairs\%20and\%20Medicines\%20 Control\%20Council\%20and\%20recommendations\%20for\%20New\%20Regulatory\%20Authority\%20 for\%20Health\%20Products.pdf (accessed 9 March 2016).

6. Summary of the Industry Task Group meeting held at 09:00 on 17 March 2015 at the Civitas Building. http:// www.mccza.com/documents/97911b47itg_meeting_minutes_march2015.pdf (accessed 20 October 2015).

7. Leng HMJ, Mutoti K, Mbelle N. Regulatory requirements for the development and registration of Leng HM], Mutoti K, Mbelle N. Regulatory requirements for the development and registration of
biosimilars in South Africa. GaBI J 2015;4(3) http://gabi-journal.net/regulatory-requirements-forbiosimilars in South Africa. GaBI J 2015;4(3) http://gabi-journal.net/regulatory-requirements-for-
the-development-and-registration-of-biosimilars-in-south-africa-2.html (accessed 19 October 2015).

8. Derbyshire M. Reducing the European healthcare budget with generics and biosimilars. GaBI J 2014;3(4):200-201. DOI:10.5639/gabij.2014.0304.046

9. GaBI Online - Generics and Biosimilars Initiative. Biosimilars approved in Europe. Mol, Belgium: Pro Pharma Communications International, 2011. www.gabionline.net/Biosimilars/General/Biosimilarsapproved-in-Europe (accessed 20 October 2015).

0. Médecins Sans Frontières. DR-TB patients, activists demand registering generic linezolid. 30 October 2014. https://www.msf.org.za/msf-publications/dr-tb-patients-activists-demand-registering-genericlinezolid (accessed 20 October 2015)

11. GroundUp Staff. Life-saving drug stopped by sole supplier. 2015. http://groundup.org.za/article/lifesaving-drug-stopped-sole-supplier_3359 (accessed 16 October 2015).

12. Allafrica.com. South Africa: Essential TB Medicine - Is it Back in Stock? http://allafrica.com/ stories/201511022739.html (accessed 9 March 2016).

Accepted 9 November 2015. 